\title{
A produção industrial e suas inibições*
}

\author{
José Pinto Antunes \\ Catedrático de Economia Politica na. \\ Universidađe de São Paulo.
}

\section{Os dados do problema - Produção - Consumo.}

Temos para nós que a Produção é o princípio e o fim da Ciência econômica.

Produzir é criar of elimidades, coisas úteis e utilidade é a qualidade do bem para satisfazer os desejos humanos. Produzir é, assim, aquietar desejos.

O problema fundamental da ordem pública está na Produção. O tamanho do bôlo e não a sua distribuição ou divisão, é que constitui a questão básica da ordem coletiva. Ensina a sabedoria popular - "onde não há pão, todos gritam e ninguém tem razão" A divisão é questão jurídica, de justiça. O produzir é tarefa econômica. Aumentar o bôlo produtivo significa, desta forma, condicionar essencialmente o feliz êxito do jurista.

Mas o problema é difícil, constante, porque não possui solução definitiva, não há solução matemática, mas de ciência social.

$\mathrm{E}$ em dois pontos bate a questão neste passo.

Preliminarmente, há o fato irremovível de que o consumo é de todos. Todos consomem, crianças, velhos, inválidos; mas a produção é de poucos - sòmente os homens válidos. Em suma, enquanto todos comem, sòmente uma minoria produz.

(*) Conferência pronunciada a convite da Federação e Centro das Indústrias do Estado de São Paulo, no forum "Roberto Simonsen". 
Então, o grande problema está em se obter, dos homens produtores, uma produção superior à própria necessidade a fim de que com os excessos à própria produção sejam alimentados (aquietados os desejos) daqueles que consomem mas não produzem. Sem êste equilíbrio entre os dois dados - produção, consumo, a ordem social é impossível. A maioria, pelo menos, precisa comer para aceitar a disciplina da autoridade pública e conter a inquietação ou revolta da minoria faminta.

o outro ponto, conseqüente, é o método social para obtenção dêsse equilíbrio fundamental à ordem pública.

A produção, necessária ao consumo, pode ser deixada livre, graças à instituição jurídica da propriedade privada. Afirma, aí, a autoridade que todos podem produzir tudo, como quiserem, o quanto quiserem e quando convier. Os excessos à própria produção serão, porém, assegurados como coisa própria (propriedade) ao seu produtor. Então, pela ânsia de acumular (enriquecer), cada um dos homens válidos, capazes para a produção, multiplica e racionaliza o seu esfôrço para superação do próprio consumo. Com os excessos, pela técnica jurídica dos contratos, através da Iroca, facilitada pela moeda e pelo critério, processa-se o equilibrio entre a produção e o consumo sob a garantia jurídica dos direitos individuais à liberdade.

"No espírito de iniciativa e organização funda-se a riqueza e a prosperidade nacional", eis o princípio fundamental a esta ordem jurídica que condiciona a solução do problema econômico da produção parcial para o consumo total. Pela liberdade dá-se a circulação dos excessos. As flôres, as jóias, o luxo, enfim, de quem acumula, é forma de circulação e distribuição voluntária (contratual) dos excessos produzidos.

Mas é possível que a Autoridade imponha critério de justiça, de ajustamento, entre a produção e o consumo; não aceitando as conseqüências naturais da liberdade de iniciativa e organização, pode a autoridade planificar a produção e racionar o consumo. É a política econômica do 
Estado autoritário - tudo dentro do Estado, nada fora do Estado, nada contra o Estado. O equilíbrio entre a produção e o consumo torna-se, então, a expressão de um ideal de justiça de que são portadores os ditadores da ordem total-econômica e jurídica.

O tema da nossa palestra não se refere a êste sistema econômico-jurídico - aí, não há a liberdade individual da produção e do consumo e não se pode falar, pois, em inibições à produção - tudo é planificado pelo Poder.

Queremos tratar do assunto dentro do sistema do constitucionalismo democrático, onde a Lei Máxima que é a Constituição, afirma as excelências da liberdade nas suas multiformes expressões. A Economia é para o Homem e não compreendemos sistema jurídico-econômico que não respeite a condição fundamental à dignidade da pessoa humana - a liberdade.

Ora, o sistema da produção pela liberdade supõe a concorrência e o lucro, como conseqüências do princípio jurídico que assegura a propriedade privada (liberdade de possuir e dispor); e onde as conseqüências forem impedidas, o princípio do sistema, o próprio sistema não funciona.

É certo que a concorrência que admitimos supõe, não só a licitude, mas, igualmente, a lealdade da competição dos preços, o que se assegura, socialmente, pelo capítulo da Ordem jurídica que denominamos o "Direito da Emprêsa", cujos capítulos fundamentais são constituídos pelo Direito Industrial e pela Legislação do Trabalho ${ }^{1}$

As inibições à produção, que analisaremos, são, portanto, os desvios do sistema de competição que supõe, também, o regime de preços.

Por outras palavras, é a falsificação dos preços pela autoridade, é a intervenção sem medida do Poder que faz a crise da Produção pelo sistema de liberdade de inicia-

(1) Ver nossa obra - "A Produção sob o Regime da Emprêsa". São Paulo, 1954, pgs. 348 e segs. 
tiva e organização. É o Poder, pela ignorância do funcionamento do sistema, que inibe o produtor de produzir, levando, assim, a ordem social ao cáos.

Principiemos a análise dos atos de desgovêrno na ordem econômica.

\section{A legislação do trabalho}

Afirmam, em sucessão, os titulares do Poder público brasileiro que: mundo.

“possuimos a Legislação Trabalhista mais avançada do

Mas isto é um mal e não um bem para a economia e para a ordem. A produção, em regime de concorrência, é afinal, a competição internacional dos custos; a legislação trabalhista mais avançada supõe o custo mais elevado do fator trabalho na concorrência dos produtores. É por esta razão que a Legislação do Trabalho é, essencialmente, internacional; a adoção nacional, dos seus preceitos, exige a generalização, a simultaneidade da adoção dos seus avanços pelos países produtores e competidores no mercado mundial. O país bom padrão, porque precursor das vantagens trabalhistas, é país vencido na concorrência.

A nossa produção, especializada em produtos gravosos, possui nesta causa a incompetência para a competência. Enquanto outros tardam, para ganhar mercados, em adotar as Convenções Internacionais do Trabalho, nós, os brasileiros, orgulhamo-nos dêste pioneirismo sentimental, mas contraproducente. Antes dos outros, aumentamos o custo da produção dos nossos produtos de exportação, dando às massas ignaras sensação de govêrno de favor, quando, na realidade, destruímos as bases econômicas da própria sustentação vital do povo.

De fato, as normas trabalhistas, que marcam a nossa Legislação do Trabalho, são de um primarismo contundente. 
A estabilidade, por exemplo, consagrada na c.L.T., escraviza o operário ao arbítrio patronal, nos 10 anos que precedem à conquista do direito ao emprêgo; conquistada a estabilidade, o operário dá de si o mínimo suficiente para não incorrer em falta grave, que autoriza a rescisão contratual.

Assim, na primeira fase, maltrata-se o pseudo-beneficiado, e, na segunda, quem perece, primeiro, é a Produção e, depois, o próprio operário, pois da emprêsa vivem todos, mas especialmente, o pessoal subordinado, cuja condição vital está no volume do salário a êste é, por sua vez, determinado pela vitalidade econômica da organização produtiva empresária.

E que dizer, então, da imposição constitucional do artigo 157, n. ${ }^{\circ}$ IV da Constituição de 1946, "participação direta e obrigatória dos operários no lucro das emprêsas?"

Verificado o lucro, os operários pedem a distribuição imediata dêle, como complemento salarial. Discordarão de todo emprêgo como capital para melhoria técnica da produção ou ampliação do negócio. Como resolver o conflito de interêsses? Se, pelo operário, trava-se o progresso econômico, decretando-se a derrota da emprêsa nacional na competição internacional de preços, a racionalização da técnica produtiva torna-se impossibilidade legal. Se, ao contrário, deixa-se a solução ao arbítrio patronal, o texto constitucional torna-se letra morta sob certo prisma, mas sob outro, será fermento suficiente para as constantes agitações sociais. E, sem paz social, sem ordem, a produção de riquezas não se faz!

Esqueceram os constituintes ou não sabiam que o regime de iniciativa privada, que reconheceram na Constituição, supõe, hoje, a produção pelo regime de emprêsa, onde o risco do negócio cabe ao empresário e, como contrapartida, o lucro é seu - o lucro é o preço do risco na produção livre. Sem a livre disposição do lucro ninguém arrisca: não vale a pena arriscar. E sem a iniciativa 
privada, sem o estímulo ao seu desenvolvimento, não è possível o regime econômico que se declarou, em princípio, na Constituição de 1946. ${ }^{2}$

Ainda, na nossa Legislação Trabalhista, exaltam-se os nossos demagogos-governantes com as excelências do princípio da irredutibilidade dos salários consagrados na c.L.T. Mas não vêem, todos, que tal imposição impede ao empregador a elevação dos salários, na fase cíclica da economia em que se acentua a prosperidade dos negócios? Como poderá o empregador fazer o seu operário participar da prosperidade da emprêsa, se, depois, na fase crítica, que se segue à ascensão cíclica, aquêle custo do trabalho, congelado, vai ser a causa de aceleração da sua ruína?

Não se diga que a Justiça do Trabalho examinará cada espécie, em conflito individual, e decidirá da redução quando ela se imponha.

Ora, a Justiça do Trabalho é a outra forma da desastrada intervenção econômica brasileira, responsável pelo travamento do nosso desenvolvimento econômico.

Começa pelo privilégio que os juristas transplantaram do campo do Direito Penal para o campo trabalhista. "In dubio. pelo operário".

Mas, é a emprêsa o fundamental. É dela, da sua prosperidade, que vive o operário. "Patrão rico, empregado remediado", já ensinava a velha sabedoria popular portuguêsa. $O$ que deverá ver o julgador trabalhista é, antes de tudo, se sua decisão condiciona ou não a vida e prosperidade da organização empresária e, em função desta observação, decidir a pretensão operária, individual ou coletiva. Então - "In dubio, pela emprêsa", porque dela vive o operário, e da atividade empresária total vive a própria nação.

Não é esta a diretiva dos poderes legislativo, executivo e judiciário do nosso país.

(2) 0 assunto foi explanado, minuciosamente, na nossa obra citada, pg. 273 e segs. 
O poder legislativo abdica das suas funções fundamentais, contra texto expresso da Constituição, e delega, tàcitamente, os seus poderes de fazer leis ao poder executivo; exemplo — a decretação do salário mínimo! $\mathrm{E}$ o judiciário, pela palavra do Supremo, guarda do limite das competências constitucionais, teme a agitação social, fraqueja na sua função e admite a delegação contra o texto expresso da Lei Magna.

A Constituição não é o que ela diz ser ou aquilo que os constituintes queriam que ela fôsse, mas o que delibera que seja a maioria da Côrte Suprema... E as massas organizadas em sindicatos, ou arrebanhadas pelos demagogos, constituem hoje o Grande Poder que dirige, de fato, os pseudos "poderes" constitucionais. .

A sentença econômica ou sentença coletiva dos nossos tribunais trabalhistas é ditada por uma justiça que não tem mais a venda nos olhos, como a antiga, que ainda figura nos ornatos dos foruns ou dos quadros de formatura de bacharẻis. ...A "Justiça" de hoje é dotada de radar, para perceber os ruídos profundos das reações operárias, a fim de seguir as inclinações delas e não impor, como deveria, o equilíbrio das classes, reconhecidas como fôrças iguais na formalidade constitucional.

Destrói-se, assim, a euritmia das fôrças econômicas que asseguraram a produção pela técnica das liberdades individuais.

Não é só. A Previdência Social decreta a aposentadoria dos homens válidos aos 55 anos!. .

Todos comem. O consumo é total. A produção é de poucos porque sòmente produzem os homens válidos.

Há, no direito brasileiro, a invalidez natural, orgânica, que existe em todos os países como condição legal das aposentadorias; mas, no Brasil, a "legislação é a mais avançada do mundo" e os válidos são legalmente inválidos, quando atingem aos 55 anos de idade!. .

Por fôrça de lei, são excluídos da produção das riquezas... 
É a burocratização da economia a modo do que acontece no setor público - 9,4 bilhões de cruzeiros são pagos, pela União, aos inativos do seu quadro burocrático.

No exército brasileiro, $28 \%$, do seu orçamento, são pała o pagamento dos inativos. E na inatividade ganhase mais do que na atividade!!!

Nunca, em país algum, tão poucos estão trabalhando para o sustento de tantos. .

\section{A legislação fiscal}

No regime que, constitucionalmente, adotamos, o lucro é a mola ou élan vital. O espírito de iniciativa e organização alimenta-se, vive do lucro; sem lucro, sem esperança de lucrar, não há iniciativa que vingue, não há ação econômica que prossiga.

Mas é contra o lucro que se volta hoje o Poder público. O Legislativo federal entrava o desenvolvimento econômico aumentando, sem medida, o corte dos lucros empresários, através da legislação fiscal, especialmente o impôsto sôbre a renda. O lucro, nesta distorção psicológica de pseudo-democracia é quase delito. $O$ comerciante sofre apodos numa concepção primitiva e superada da sua função. Acham-no inútil, na racionalização produtiva, quando, ao contrário, é êle o criador da utilidade tempo, utilidade lugar e utilidade quantidade, enfim, um produtor como aquêles que mais o sejam. Congela, o poder executivo, o preço de venda; e deixa livre o preço do custo; assim, numa torquês, estrangula o lucro e espera o impossível, isto é, que a iniciativa privada, mola do regime, prossiga na produção de riqueza.

O lucro extraordinário, para esta legislação fiscal vesga, é um crime. Amputa-o, pelo padrão da mediocridade econômica, o legislador que, com isso, pretende assegurar-se da adesão e do aplauso das massas eletivas. Mas, o lucro extraordinário é o preço do risco extraordinário. 
Como tirar da virtualidade as riquezas brasileiras sem o prêmio adequado ao grande risco das explorações econồmicas?

A exploração do petróleo, por exemplo, exige riscos extraordinários e sòmente a possibilidade de lucros, igualmente extraordinários, permitiria a sua exploração pela iniciativa privada. Êste foi e é o caso da indústria petrolífera americana.

Os bandeirantes, sem a atração das verdes esmeraldas, não teriam traçado, como traçaram, as fronteiras brasileiras...

Além de tudo, é o lucro empresário a fonte primacial dos capitais necessários ao desenvolvimento econômico do país. O nosso desenvolvimento, sem a caridade dos irmãos ricos, só seria possível pela segurança jurídica dos lucros, que exerceria a função propulsora ou espicaçadora das iniciativas privadas. Sem proteção ao lucro sòmente a iniciativa estatal é viável e com esta, também, necessita de capitais, que não se produzem no país, pelas razões apontadas, para se sair do subdesenvolvimento, torna-se preciso submeter a Nação às condições políticas do empréstimo de potências estrangeiras e, tudo isso, à custa da soberania nacional. A riqueza é condição da liberdade, até nas relações entre os povos.

Ideologias Nacionais. A nova ordem econômica internacional

O povo, corrompido pelos demagogos, condena o empresário, considerando-o insaciável sugador das energias das classes pobres - é o "tubarão", na gíria nacional, e tôda medida, tomada contra a sua atividade econômica, identifica-se com a defesa da economia popular. Assim, o legislador ignorante, na busca da popularidade, investe contra o homem de negócios, travando-lhe os movimentos, cortando-lhe as vantagens produtivas, não dando tento, por ignorância ou má fé, que o estímulo à produção é sufo- 
cado com sacrifício de todo o sistema econômico fundado na livre iniciativa.

Por outro lado, os nacionalismos voltam-se contra o capital estrangeiro, de que tanto necessita o país para fugir à miséria resultante do subdesenvolvimento econômico. É o irracional que governa a economia, porque êsse mesmo nacionalismo, que recusa o capital privado, porque pertence à alienígena, aceita e reclama o empréstimo de potências estrangeiras, cujas condições de auxílio são, muitas vêzes, a total renúncia do povo ao direito, fundamental a tôdas as liberdades individuais, de auto determinação política.

Ainda, as ideologias políticas embaraçam as relações comerciais entre os povos, criando barreiras políticas complementares às barreiras alfandegárias; enquanto, estas, ainda se justificam, como fase preparatória ao desenvolvimento econômico, aquelas são carregadas de irracionalismo, porque carreiam riquezas para os países intermediários, do comércio triangular, que se estabelece como reação econômica natural à contenção da circulação dos bens no mercado universal.

Agravando tudo, surge, agora, uma tendência de agrupamentos entre Estados, na defesa dos interêsses econômicos, que põem em comum. $O$ mercado comum europeu, incluindo os países africanos, subordinados à política continental, estabelece um regime autárcico para os produtos desta zona econômica, com real sacrifício para os produtos similares das economias isoladas dos países americanos. Derrubam-se as fronteiras, naquela aliança econômica, como se fôra um só país e levantam-se defesas comuns contra a importação de tudo aquilo que não seja produzido pelos países da nova comunidade econômica. Aí, também, perde-se a esperança dos antigos acordos bilaterais, de nação a nação, facilitando a troca de mercadorias, pois o mercado comum europeu, com perto de 300 milhões de consumidores, não vê interêsse em barganhar com mercados de 60 milhões de hipotéticos consumidores, 
como sejamos americanos do Brasil, de baixo rendimento per capita.

Perdemos o mercado para os nossos produtos, similares aos africanos, beneficiados pela nova política econômica do mercado comum europeu, e não vemos possibilidade de reconquistá-lo, porque somos pobres na oferta a fazer, que consiste no modesto mercado consumidor brasileiro para os produtos do imenso mercado produtor de quase dois continentes.

Seria o mercado comum americano o recurso para o restabelecimento do equilíbrio contratual perdido? pergunta que deixamos no ar para resposta em outra oportunidade.

O setor público da economia. Os malefícios da exploração estatal pelas sociedades de economia mista.

Pelos motivos expostos e muitos outros, a iniciativa privada, desencorajada e até perseguida pelo poder público, torna-se omissa ou insuficiente na exploração de riquezas potenciais do país. Então, a intervenção do Estado se amplia e, hoje, a constituição de sociedades, ditas de economia mista, vem a ser o modêlo jurídico da extensão do setor público da economia.

De fato, $51 \%$ das ações destas sociedades são atribuídas ao Poder público e o capital privado, minoritário, obedece, submisso, à direção econômica da autoridade estatal. São os políticos, ligados ao Poder, os nomeados para a direção do negócio, sem a prova da capacidade de exercício de atividade econômica. Ao invés de lucro, diz-se que o objetivo da exploração estatal é servir. De fato, serve-se ao pessoal empregado, elevando-se, sem medida, o custo do fator trabalho, atendendo-se às constantes reivindicações salariais. A utilidade produzida, no entanto, por maior custo, continua a ser vendida pelo mesmo preço, para servir o povo ou aos usuários. O deficit, ao 
invés do lucro, é a regra das atividades industriais do Estado. O prejuízo, então, é coberto pelo orçamento estatal, através do acréscimo dos tributos; os tributos são arrancados de quem produz pelo corte, continuado, nos minguados lucros empresários, fonte principal dos novos capitais de que carece a Nação para sair do subdesenvolvimento...

$\mathrm{E}$, assim, numa cadeia de erros, vai o intervencionismo estatal impelindo o país para o caos econômico e social, pela destruição das condições da livre iniciativa, quando o regime constitucional assegurará que nela se fundaria a ordem econômica da Nação!.

Os regimes mestiços são também improdutivos. Não se pode admitir e negar o mesmo princípio sem introduzir a contradição na ordem econômica e jurídica. Não podemos admitir a democracia na ordem política e negá-la na ordem econômica. A liberdade é uma só. A liberdade cria e disciplina. Mas a liberdade pede garantias ou condições jurídicas. Afirmá-la e não a garantir, equivale a negá-la.

Escolha o país o método de sua produção: liberal, com o reconhecimento e proteção efetiva da livre iniciativa, ou autoritário, com o reconhecimento da exclusiva iniciativa estatal. O pé nos dois barcos é impossível. A vela acesa em um altar é incompatível com a acesa em outro. 0 setor público da economia tende à extensão totalitária; a simultaneidade dos dois setores - privado e público, o equilíbrio entre ambos, é difícil ou impossivel; no fundo, é o passeio fatal da panela de barro na companhia da panela de ferro... 